\title{
RELAÇÕES PRELIMINARES ENTRE A GESTÃO ESPORTIVA E O PROFISSIONAL DE EDUCAÇÃO FISICA
}

Tiago Perez Vieira

Sérgio Stucchi

\section{Resumo}

Este artigo tem como objetivo trazer para o estudante de Educação Física elementos para discussão sobre gestão esportiva. Principia-se com a análise da atual contextualização deste termo, do perfil profissional já identificado em pesquisa, pelas suas competências e relações do educador físico com a gestão esportiva. Sugere-se que o profissional desta área, por sua formação, já detém conhecimentos específicos do esporte para um posterior desenvolvimento das competências necessárias e das também identificadas no perfil do gestor esportivo.

\section{Palavras-Chave}

Gestão esportiva; Gestor esportivo.

\section{PRELIMINARY RELATIONS BETWEEN SPORTIVE MANAGEMENT AND THE PROFESSIONAL OF PHYSICAL EDUCATION}

Tiago Perez Vieira

Sérgio Stucchi

\begin{abstract}
The main objective of this article is to bring to the Physical Education students elements for discussion about sports management. Starting with an analysis of the current contextualization of this term and the professional identified before, through the competences and relations of the physical educator with the sports management. In addiction, it is suggested that the physical education professional, because of his/her formation, has already developed sports specifics knowledge in order to a later improvement in required competences and those identified in the sports management profile.
\end{abstract}

\section{Key-Words}

Sport business; Sport manager; 


\section{INTRODUÇÃO}

Estamos numa época em que a competição pelo mercado de trabalho se torna acirrada a cada dia. Os canais de informação permitem acesso com muita velocidade para as renovações de conhecimentos e tecnologias, trazendo para o mercado de trabalho atual (de hoje em dia), tendências globais em todas as suas relações. Esse dinamismo do mundo hoje tem um ponto a ser destacado por Zouain e Pimenta (2003, p. 1)

A proliferação da tecnologia e o crescimento da automação na produção e nos serviços aliviaram a sociedade da necessidade de incremento nas horas diretas de trabalho. Como resultado, houve um engajamento nas atividades esportivas e de lazer pelas pessoas ao redor do mundo.

Torna-se necessário o atendimento a uma demanda de mercado que se proliferou desordenadamente nos últimos anos, a busca pelas atividades físicas e a formação do profissional para atendê-las. Como todo mercado, necessitamos de pessoas capacitadas a efetuar certas tarefas, e para isso precisamos identificar as necessidades desse profissional.

Onde esse profissional atua?

Em escolas, clubes, academias, administração pública, empresas inovadoras em esportes, entre outras. Qualquer estrutura administrativa que tenha como o foco o esporte e seu desenvolvimento. Esse mercado do esporte em 2002 no Brasil gerou R \$ 42 bilhões, só em venda de artigos esportivos (atacado varejo e industrial). No âmbito mundial, segundo a FIFA, só o futebol, movimenta cerca de 250 bilhões de dólares ao ano.

Essa magnitude de investimentos necessita recursos humanos que não seja mais somente o administrador ou gestor esportivo e que tenha sido um ex-atleta, ou outra pessoa qualquer. O mercado da prática esportiva hoje necessita de um profissional com formação especifica. Para isso, analisaremos o perfil proposto por Zouain e Pimenta (2003), com as definições da área da gestão esportiva, para estabelecermos alicerces de uma discussão coerente e desenvolvimentista.

Observações de uma realidade próxima, empiricamente demonstram a falta de gestor esportivo especializado e sua necessidade tanto em instituições públicas como particulares. Isso deve ser levado em consideração, pois, essa premência já foi identificada a muito tempo, embora não tenha sido sanada. Investigar e apontar as razões e os porquês dessa deficiência, seria muita pretensão nossa, mas escolheremos outro caminho para a análise. 
Utilizando a óptica do educador físico, pela sua formação, de como o profissional dessa área vê possibilidades de gestão no seu campo de atuação, e de como os conceitos relacionados á gestão esportiva estão sendo trabalhados nas pesquisas analisadas. Estabelecendo relações para que haja uma autonomia administrativa do profissional, conhecendo os meandros dos conteúdos das atividades propostas.

\section{PROCEDIMENTOS METODOLÓGICOS}

Através de uma revisão bibliográfica, baseada em publicações especificas sobre gestão esportiva, perfil do profissional atuante na área e gestão de recursos humanos (no que tange a detecção de competências para um profissional), trazendo uma discussão sobre esse ambiente.

Tratando a estrutura de mercado, as relações de trabalho do educador físico, os campos de trabalho de uma forma genérica onde o cenário analisado é descrito por jornais, revistas, Internet e o contato com a área da Educação Física.

\section{GESTÃO ESPORTIVA}

Há uma grande confusão com os termos administração esportiva e gestão esportiva. Essas denominações são utilizadas concomitantemente, já que esses termos variam de acordo com o país, e a teoria administrativa escolhida. Aqui utilizaremos o termo gestão esportiva, pois ele engloba uma maior designação de funções e capacidades segundo Parkhouse (1996) citado por Zouain e Pimenta (2003, p. 6$)$

A gestão engloba todas as áreas relativas ao esporte como: turismo, hotéis, equipamentos, instalações, investimento público e privado no setor de fitness, merchandizing, esportes escolares e profissionais. Enquanto a administração esportiva seria mais limitada e sugere um foco nas relações esportivas e escolares.

Vemos nas palavras de Parkhouse uma amplitude maior de atuação ao nos identificarmos com o termo gestão esportiva, e ele já delimita o termo administração esportiva como uma área restrita, que analisada pela ótica dos educadores físicos, veremos que a formação acadêmica também engloba o setor fitness, e de turismo. Isto pode estar próximo de uma definição semelhante à denominação da North American Society for Sport Management (Sociedade Norte Americana para Gerência do Esporte - NASSM), que define a gestão esportiva como:

[...] um agrupamento interdisciplinar, que tem como características a ênfase nos temas; direção, liderança e organização esportiva, incluindo questões comportamentais, ética, marketing, comunicação, finanças, economia, responsabilidade social, legislação e preparação profissional. (NOLASCO et al., 2005, p. 760). 
Para Mullin (1993) citado por Zouian e Pimenta (2003, p. 8), “a gestão esportiva tem como primeiro objetivo promover as atividades esportivas, produtos e serviços, com ênfase nas funções de planejamento, organização, direção e controle".

Outra referência ao termo, é encontrada no Atlas do Esporte no Brasil (2005) organizado pelo Professor Lamartine Pereira da Costa (que é uma referência para a gestão esportiva, pois foi um trabalho pioneiro no Brasil, na identificação de relevâncias para o esporte brasileiro), onde segundo Nolasco et al. (2005, p. 760) ”o termo administração esportiva é uma denominação histórica dessa área de conhecimento, e gestão é um nome apropriado para as necessidades da realidade". Estes autores ainda denominam a gestão, como uma organização racional e sistemática das atividades físicas e esportivas, de uma entidade ou grupo que fazem acontecer essas atividades, tanto para a participação na alta competição, quanto para o nível ou participação popular, ocasional ou regular, das práticas de lazer e na busca da saúde.

Para nos identificarmos com esses termos, utilizaremos o conceito de gestão esportiva proposto por Nolasco et al. (2005), pois, nessa conceituação há uma previsão de desenvolvimento do esporte, pelo fato de ser um educador físico, organizando e sistematizando suas atividades, estudando o fenômeno esportivo, desenvolvendo conhecimentos específicos para a implementação do mesmo.

Podemos ver a diferença na formação dos conceitos, quando uma tende a atender uma corrente administrativa destacando termos como, investimento, economia e merchandising, enquanto a outra aponta para uma especialização, uma melhor preparação, no que diz respeito à organização de idéias sistematizadas para um bom desenvolvimento administrativo nas atividades físicas e esportivas.

Como podemos ver, apesar de serem diferentes áreas de conhecimento (Administração, Educação Física), essas vertentes formam os pilares da gestão esportiva como lembrados por Parkhouse (1996) citado por Zouian e Pimenta (2003, p. 8), que “o conceito de gestão esportiva se divide em: gestão de negócios e esporte".

Para o educador físico, como poderíamos resolver essa questão e formar um conceito?

$\mathrm{O}$ conceito de gestão esportiva para o educador físico, se assemelha às relações gerenciais de seu trabalho, não importando o tamanho da estrutura administrativa. O educador físico que está lidando com a gestão esportiva, esta trabalhando com a sua área de pesquisa, adicionando conceitos necessários para estas ações e mantendo relações indiretas com gestão de negócios, que podem ser desmembrados de acordo com determinadas correntes bibliográficas. 


\section{COMPETÊNCIAS PROFISSIONAIS}

Para começarmos a analise de um perfil profissional, precisamos trazer alguns conceitos para o leitor, lembrando que esse trabalho também visa o desmembramento de teorias para o profissional de educação física.

Primeiro, devemos entender o como classificar as habilidades ou competências do gestor. Pesquisando sobre o assunto, percebemos que a teoria muda constantemente, e o termo que descreve melhor esses itens propostos é competência. Segundo Zarifian (1999) citado por Fleury (2002, p. 55), "competência é a inteligência prática de situações que se apóia nos conhecimentos adquiridos e os transforma com tanto mais força quanto maior for a complexidade das situações". (FLEURY, 2002, p. 55). Já Le Boterf (1995) citado por Fleury (2002), define competência como "o entrecruzamento de três eixos, formados pela pessoa (sua biografia, socialização), por sua formação educacional e por sua experiência profissional". Mas o conceito de competências não abrange apenas essas vertentes, como foi brevemente comentada nesses trechos. Segundo Fleury (2002), "competência é um saber agir responsável e reconhecido que implica mobilizar, integrar, transferir conhecimentos, recursos, habilidades, que agregue valor econômico a organização e valor social ao individuo". (FLEURY, 2002, p. 55).

Analisando as denominações, vemos que não basta o individuo ter um conhecimento acadêmico, uma experiência profissional, uma habilidade ou capacidade especifica. Os fatores de transmissão dessas características e condições de utilizá-las, são de extrema importância, para o sujeito e para a organização. Nessa linha de pensamento, veremos essa tabela inspirada por Le Boterf exposto por Fleury (2002).

\section{Quadro 1 Competências para o Profissional}

\begin{tabular}{|c|c|}
\hline Saber agir & $\begin{array}{l}\text { Saber o que e por que faz } \\
\text { Saber julgar, escolher, decidir }\end{array}$ \\
\hline Saber mobilizar recursos & Criar sinergia e mobilizar recursos e competências \\
\hline Saber comunicar & $\begin{array}{c}\text { Compreender, trabalhar, transmitir informações, } \\
\text { conhecimentos }\end{array}$ \\
\hline Saber aprender & $\begin{array}{l}\text { Trabalhar o conhecimento e a experiência; rever } \\
\text { modelos mentais; saber se desenvolver. }\end{array}$ \\
\hline Saber se engajar e se comprometer & $\begin{array}{l}\text { Saber empreender, assumir riscos. } \\
\text { Comprometer-se }\end{array}$ \\
\hline Saber assumir responsabilidades & $\begin{array}{l}\text { Ser responsável, assumindo os riscos e as conseqüências } \\
\text { de suas ações, sendo por isso reconhecido }\end{array}$ \\
\hline Ter visão estratégica & $\begin{array}{l}\text { Conhecer e entender o negócio da organização, seu } \\
\text { ambiente, identificando oportunidades e alternativas. }\end{array}$ \\
\hline
\end{tabular}


O Quadro 1 explica o porquê dessas características do profissional serem postas como parte do conceito de competência. A forma que o individuo interage com a organização, é essencial para uma definição de competência, já que esse conceito visa identificar fatores para a análise dos fenômenos no trabalho.

As pesquisas sobre competência parecem estar voltadas para o âmbito organizacional, mostrando que o administrador identifica competências em sua organização detectando-as em seus funcionários, capacitando-os a cumpri-las.

Partindo dessa óptica, quais seriam as competências do gestor na organização esportiva? que visão de administração o profissional em analise necessitaria adquirir? Partindo dessa configuração genérica de Le Boterf, podemos ver que as ciências administrativas já têm avançado nos conceitos de competências. Pela pesquisa de Zouain e Pimenta, o conceito de competência no trabalhado, ainda é o de habilidades que capacitam o individuo para algo, e os autores citam a dificuldade em se estabelecer uma definição consistente do termo competência. Ainda temos também Parkhouse (1991) citado por Zouain e Pimenta (2003,), destacando como competências: "habilidades básicas, comunicação, marketing e vendas, programação de eventos, supervisão e gestão de recursos humanos, gerencia de instalações e gerencia fiscal".

A visão nesta pesquisa em gestão esportiva, de como as competências funcionam, ainda tem definições limitadas por ser uma área de formação recente. Existem dificuldades em estar sempre em paralelo como as novas teorias administrativas e gerenciais, exigindo estudos que fazem aproximações das progressões de um espaço já conquistado, ou seja, o da Administração como ciência.

Tentaremos a partir do conceito de competência proposto por Fleury (2002), adaptar as conclusões de Zouain e Pimenta (2003), para detectarmos essas competências na formação do profissional de educação física.

\section{PERFIL DO GESTOR ESPORTIVO}

Ao pesquisarmos o perfil do gestor esportivo, encontraremos pouca bibliografia especializada. Devido a este fator, utilizaremos os perfis pesquisados por Zouain e Pimenta (2003, p. 4), que fizeram uma pesquisa através do seguinte questionamento: 
"Qual o perfil profíssional necessário ao gestor das organizações de administração do esporte, de forma a atender às reais necessidades que são impostas, na atualidade, pelo contexto do ambiente esportivo brasileiro?"

A pesquisa partiu de uma análise bibliográfica, com estudos específicos nos EUA, Austrália e Federações Internacionais. A partir desses estudos, além de mais uma pesquisa de campo com os gestores esportivos do Brasil de maior renome no mercado, estabeleceu-se perfis específicos do gestor esportivo que atendeu às necessidades pesquisadas em cada lugar.

Analisando primariamente a tabela a seguir, vemos particularidades entre o perfil genérico, detectado por pesquisas internacionais e ambos os perfis demonstrados na tabela relativos ao cenário brasileiro. Restringiremos a análise na esfera dos profissionais brasileiros, pois para discutirmos o ambiente internacional teríamos que ter um conhecimento mais profundo da formação profissional e das concepções utilizadas no pensamento da Educação Física nesses locais.

Quadro 2 Perfis a serem Analisados

\begin{tabular}{|c|c|c|}
\hline $\begin{array}{c}\text { Perfil do } \\
\text { Profissional } \\
\text { Genérico } \\
\text { (Mundial) }\end{array}$ & $\begin{array}{c}\text { Perfil do } \\
\text { Profissional em } \\
\text { atividade no } \\
\text { Brasil }\end{array}$ & $\begin{array}{c}\text { Perfil do } \\
\text { Profissional } \\
\text { esperado no Brasil }\end{array}$ \\
\hline $\begin{array}{l}\text { Marketing e } \\
\text { Vendas }\end{array}$ & $\begin{array}{l}\text { Conhecimento de } \\
\text { Esportes }\end{array}$ & $\begin{array}{l}\text { Conhecimento de } \\
\text { Esportes }\end{array}$ \\
\hline $\begin{array}{c}\text { Planejamento } \\
\text { Estratégico }\end{array}$ & $\begin{array}{l}\text { Habilidades em } \\
\text { Negociação }\end{array}$ & $\begin{array}{c}\text { Planejamento } \\
\text { Estratégico }\end{array}$ \\
\hline $\begin{array}{c}\text { Programação de } \\
\text { Eventos }\end{array}$ & Processo Decisório & Processo Decisório \\
\hline Comunicação & $\begin{array}{l}\text { Lidar com } \\
\text { reclamações }\end{array}$ & $\begin{array}{c}\text { Lidar com } \\
\text { Reclamações }\end{array}$ \\
\hline $\begin{array}{l}\text { Conhecimento } \\
\text { Fiscal e Legal }\end{array}$ & $\begin{array}{c}\text { Conhecimento } \\
\text { Legal }\end{array}$ & $\begin{array}{l}\text { Captação de } \\
\text { Recursos }\end{array}$ \\
\hline Gestão de Pessoas & $\begin{array}{c}\text { Supervisão de } \\
\text { Recursos Humanos }\end{array}$ & $\begin{array}{l}\text { Motivação dos } \\
\text { Funcionários }\end{array}$ \\
\hline
\end{tabular}

Fonte: Adaptado de ZOUAIN, PIMENTA (2003, p. 22).

Voltando ao profissional brasileiro, demonstrado no Quadro 2, podemos ver que o perfil esperado é muito semelhante ao já encontrado no profissional em atividade no Brasil, tendo como características as semelhanças de competências descritas. Por isso, quando analisarmos as competências do gestor brasileiro, incluiremos como referências: conhecimento de esportes; habilidade em negociação; planejamento estratégico; processo decisório; lidar com reclamações; conhecimento legal; captação de recursos; motivação dos funcionários; supervisão de recursos humanos. 
Para isso colocaremos sempre essas competências propostas pelo perfil analisado, como item que abrange as vertentes de Le Bouterf citado por Fleury (2002); saber agir, saber mobilizar recursos, saber comunicar, saber aprender, saber engajar-se e a se comprometer, saber assumir responsabilidades e ter visão estratégica. Analisaremos esses itens de uma forma que, independentemente da exposição ser baseada em conceitos ultrapassados, já que essa é a nossa base de parâmetros, a identificação dessas características no profissional de educação física. Como as pesquisas, ao que parece, não apresentam definições exatas sobre competência, ao realizarmos este estudo não conseguiremos identificar quais fatores englobam esse conceito. Para isso, quando identificarmos as características dessas competências, utilizaremos conhecimentos gerais, que não serão aprofundados nesse estudo, pois será feita uma breve relação do gestor com o educador físico.

\section{CONHECIMENTO DE ESPORTES}

Desnecessário se faz falarmos dos conhecimentos em esportes pelo profissional de educação física, devido à certeza da tradição deste conhecimento na história dos cursos de formação dessa área. Porém, deixamos um alerta para a formação acadêmica desses profissionais, que num futuro próximo analisaremos este conhecimento dos que exercem a profissão. Algumas escolas de formação criam um educador físico conhecedor do esporte em todas as suas vertentes, a antropologia, a sociologia, a psicologia, o fenômeno esportivo, as teorias de treinamento, conceitos da fisiologia, anatomia, bioquímica, biomecânica, lesões e teorias do lazer. Isso torna um profissional altamente capacitado para atender a qualquer tema relacionado ao esporte, e esses conhecimentos darão subsídios para esse profissional entender das atividades gerais dos negócios, baseados sempre nos preceitos da Educação Física.

\section{HABILIDADE EM NEGOCIAÇÃO}

Trazendo essa formação para um planejamento estratégico, a habilidade em negociação é uma competência necessária para o gestor buscar atingir objetivos através de ações eficazes e racionais. Segundo Bazerman e Neale (1998), negociar racionalmente significa "tomar as melhores decisões para maximizar seus interesses[...], [...] saber como chegar ao melhor acordo e a não ficar satisfeito com um acordo qualquer." (BAZERMAN, NEALE, 1998, p. 17). Negociação racional não nasce com a pessoa, como outras competências, as influências que permeiam essa competência fazem parte de um processo de aprendizagem que vai desde a sua formação moral até a acadêmica. 
Para o educador físico graduado, a defasagem está na questão dos conhecimentos específicos sobre negociação, como conteúdo a ser adquirido na escola de formação, e seu aproveitamento quanto ao aprendizado já é uma competência demonstrada para um futuro bom profissional. Adaptar o poder de negociação das aulas em colégios, dos treinos propostos, dos objetivos a serem alcançados, certamente é estar relacionando os conteúdos a serem "vendidos" ao profissional a ser treinado para essa função de gerente. Transpor esse negociar diário junto com o aprendizado das particularidades do conhecimento em negócios, pode ser uma boa estratégia futura.

\section{PLANEJAMENTO ESTRATÉGICO}

Para definirmos essa competência temos que pensar em administração estratégica. O planejar, implementar e o controlar estrategicamente, se enquadram nessa administração. Segundo Wright, Kroll e Parnell (2000. p. 45) a administração estratégica é:

um processo continuo de determinação da missão e objetivos da empresa no contexto de seu ambiente externo e de seus pontos fortes e fracos internos, formulação de estratégias apropriadas, implementação dessas estratégias e execução do controle para assegurar que as estratégias organizacionais sejam bem sucedidas quanto ao alcance de seus objetivos.

Essa administração estratégica se assemelha muito ao processo de periodização utilizados em todos os treinamentos e um bom exemplo aqui é no planejamento de aulas. Nessas funções o profissional de educação física planeja as suas intervenções e propõem objetivos a serem alcançados, controlando, no decorrer dos processos, se os resultados parciais desses objetivos estão sendo alcançadas, fazendo os ajustes necessários. Na concepção da aprendizagem de competências, o educador físico está propício a adaptar as suas relações de planejamento para a capacitação do gestor esportivo.

\section{PROCESSO DECISÓRIO}

Quando tomamos decisões devemos pensar numa escolha coerente que propiciará um melhor retorno á organização. Segundo Robbins (1999, p. 68-69) esse processo é conhecido como processo de tomada de decisão racional, onde o tomador de decisão necessita desde ter informações completas sobre a situação problema, analisar as possibilidades e possíveis conseqüências, importâncias e critérios claros e constantes no decorrer do processo de decisão, e garantir ao máximo a relação perdas e ganhos num saldo positivo para a organização. 
Não podemos confundir decisão com intuição, para isso Robbins identifica como uma virtude do tomador de decisões a criatividade, pois uma visão simples de solução não necessitaria de uma intervenção racional, a criatividade extrapola a realidade colocando os pensamentos em outros patamares de analise. Como outras competências, o processo decisório pode ser desenvolvido tecnicamente no educador físico, na medida em que a criatividade permeia em nossas ações. As etapas do processo decisório podem ser aprendidas e treinadas em qualquer individuo que tenha que lidar com solução de problemas, isso inclui o educador físico em suas atuações.

\section{LIDAR COM RECLAMAÇÕES}

Reclamações no âmbito dos negócios podem ser caracterizadas como reclamações do consumidor devido a uma falha qualquer no serviço. Por exemplo quando vamos começar um treino de musculação e o aluno faz uma reclamação tanto sobre a aula como também numa indisposição momentânea, o papel do educador físico é de contornar essa reclamação e criar alguma alternativa para conquistar o seu objetivo, que seria a aula. Essa atividade do educador físico é uma competência que no mundo dos negócios pode ser de muita valia, pois esse contato com as reclamações momentâneas se encaixa num processo de capacitação do gestor esportivo.

\section{CONHECIMENTO LEGAL}

Todo profissional deve conhecer a legislação que o cerca, a autonomia de exercer a profissão necessita disso. O conhecimento sobre a legislação especifica para empresas deve ser adquirido pelo educador físico, já que ele tem conhecimento sobre as leis esportivas e de incentivo fiscal, que o ajudará na próxima competência.

\section{CAPTAÇÃO DE RECURSOS}

É a competência que requer uma justificativa para um financiador do projeto. Para captar recursos, o profissional tem que conhecer o produto que está oferecendo, nesse caso, estamos falando da atividade física. E quanto mais critico for o financiador, mais subsídios teóricos serão necessários para a captação de recursos. As técnicas de apresentação dos projetos devem ser incluídas nessa competência. O profissional de educação física tem um aprendizado acadêmico que o possibilita falar em público devido às muitas vivencias no decorrer do curso, faltando apenas uma lapidação nas técnicas especificas. 


\section{MOTIVAÇÃO DOS FUNCIONÁRIOS}

Essa competência pode ser facilmente suprida pelo educador físico, pois, diariamente os alunos são motivados a estarem fazendo o que lhes foi proposto, estimulando-os individualmente e em equipes a melhorar em determinados momentos. Essa competência é tão evidente nos educadores físicos que é comum treinadores ministrarem palestras sobre motivação em empresas.

\section{SUPERVISÃO DE RECURSOS HUMANOS}

Talvez a mais difícil competência a se conquistar seja a de saber delegar e cobrar funções, pois, engloba uma gama de competências como a liderança por exemplo. O trabalho em equipe assemelha-se ao de um time esportivo, aonde cada um tem a sua função e depende do outro para a conquista dos objetivos do grupo.

As relações entre o educador físico e essas competências, são apenas exemplos de como o profissional de Educação Física pode ser reavaliado em sua capacitação e colocação na gestão esportiva. A formação acadêmica comum a todos os educadores físicos (sem entrar nos méritos sobre a qualidade de cada currículo), faz parte do desenvolvimento de competências, faltando uma melhor preparação técnica para a inserção desse profissional na área de gestão esportiva.

\section{CONCLUSÕES}

Reconhecido o cenário proposto, que abrange a gestão esportiva em sua contextualização e o perfil profissional pesquisado nas relações do educador físico frente a esse desenvolvimento da área, percebe-se que a Educação Física não está impondo os seus preceitos teóricos, acerca de um direcionamento para as pesquisas especificas sobre o tema.

O termo gestão esportiva não contém direcionamentos que norteiem o educador físico, pois, algumas das teorias revistas, são sobre gestão de negócios voltadas ao esporte. Algumas relevâncias para o educador físico foram observadas na teoria de Nolasco (2005), onde foi compactuado que a gestão esportiva se faz para atender as necessidades organizacionais e institucionais do profissional das atividades físicas, partindo para um pensamento sobre o desenvolvimento da área em questão que deve ser voltado para os anseios da Educação Física, em relação á sua gestão. 
Conseqüentemente, desse estudo, só poderemos abrir uma discussão sobre os caminhos da teoria em gestão esportiva. Direcionar nosso posicionamento favorável a uma complementação da área de Educação Física em prol da gestão esportiva. Para isso, posteriormente, deveremos identificar fatores nas teorias da Educação Física que satisfaçam a formação de uma diretriz para o conceito de gestão esportiva, no que corresponderia as seguintes questões: O que a Gestão Esportiva abrange? Quais são seus objetivos? Como são as estratégias de ação?

Tendo em vista essa falta de foco das teorias, as pesquisas das Ciências Administrativas tem se apropriado do conhecimento acadêmico, formatando-o como um negócio direcionado ao esporte mercadoria, limitando o papel das teorias da Educação Física na contextualização sobre gestão esportiva, acarretando um desenvolvimento técnico, aonde são frisados conceitos de como fazer negócios, e não de como gerir o esporte.

Essa tendência em negócios, é também percebida no perfil proposto por Zouani e Pimenta (2003), quando vemos em suas conclusões um direcionamento das competências do gestor esportivo, para duas disciplinas: Administração e Comunicação.

Baseado em Le Boterf (1995), citado por Fleury (2002), vemos que as competências individuais fazem parte de um processo que abrange todo o aprendizado conquistado pelo individuo, desde seus conceitos morais até o seu conhecimento acadêmico. Ao invés das competências serem lacunas a serem preenchidas, o desenvolvimento dessas características deve fazer parte de um processo continuo, que depende das necessidades da organização ou instituição, que ainda tem a função de treiná-los para determinada função.

Ficou evidente que o profissional de educação física deixa a desejar em relação aos conhecimentos técnicos em gestão de negócios, mas ainda frisamos que toda competência pode ser aprendida. Por isso relacionamos o educador físico em suas atuações com as competências requeridas pela pesquisa. Fazendo uma ressalva as relações exemplificadas, que podem ser mais bem desenvolvidas de acordo com a abordagem proposta, as relações humanas são identificadas e desenvolvidas em qualquer individuo normal.

Nas considerações finais de Zouani e Pimenta (2003), vemos que há uma intenção em solucionar a problemática da capacitação do gestor esportivo, com novos estudos para a implementação de currículos 
acadêmicos, para refletir e ensinar tais competências exigidas. Em contrapartida, temos uma falta de foco, já demonstrada anteriormente, que não nos garante um crescimento seguro dos ideais que acercam a gestão esportiva. Isso tem certa influência no desenvolvimento científico acadêmico e distancia o educador físico das concepções, tanto na formação do conceito, como no enquadramento do gestor esportivo.

Para isso é proposto que quando formos desenvolver o conceito de gestão esportiva, devemos primar pela questão de como o fenômeno esportivo se ramifica para a gestão de negócios, e não de enquadrarmos as atividades físicas como uma forma de negócio, um produto a ser vendido. Seguindo esse raciocínio, quando pesquisarmos sobre as competências de um gestor esportivo, veremos que essas capacidades são desenvolvidas através de um longo aprendizado e pela capacitação dada pelo gestor de recursos humanos, que identifica competências necessárias à instituição para cada cargo. Então, podemos apontar como relevante uma pesquisa sobre a atuação desse profissional, não apenas em relação às suas capacidades mas sim, também, sobre como o profissional de educação física pode ser agregado a essas exigências do mercado dos negócios, através de uma teoria geral de gestores, estabelecendo parâmetros de análise para uma futura adaptação consistente na realidade brasileira.

Não há necessidade de começarmos a pesquisar Gestão Esportiva e deixar de lado o que já foi pesquisado pelas Ciências Administrativas. Para isso precisamos adaptar as teorias administrativas para a Educação Física, destacando fatores que direcionem o educador físico para os conceitos que cercam a gestão esportiva. Assim termos um desenvolvimento coerente prezando pelo esporte e seus profissionais, seus consumidores e seus praticantes.

\section{REFERÊNCIAS}

BAZERMAN, M. H.; NEALE, M. A. Negociando racionalmente. São Paulo: Atlas, 1998. Cap.1, p. 1721.

FLEURY, M. T. A gestão de competência e a estratégia organizacional. In: . et. al. As pessoas na organização. São Paulo: Gente, 2002. Parte 1, p.51-60.

LE BOTERF, G. De la conpeténce. essai sur un attacteur étrange. Paris : Les editions d'organizations, quatriéme tirage, 1995 apud FLEURY, M. T. A gestão de competência e a estratégia organizacional. In: FLEURY, M. T. et. al. As pessoas na organização. São Paulo: Gente, 2002. 
MULLIN, B. ; HARDY, S.; SUTTON, W. Sport marketing. Illinois: Human Kinetics, 1993 apud ZOUANI, D. M.; PIMENTA, R. C. Perfil dos profissionais de administração esportiva no Brasil. In: WORLD SPORT CONGRESS. Barcelona, 2003. Disponível em: $<$ http://www.ebape.fgv.br/academico/asp/dsp_rap_sobre.asp> Acesso em : 06 jun. 2005. NOLASCO, V. P. et. al., Administração/Gestão Esportiva. In: COSTA, L. P. da (Org.). Atlas do esporte no Brasil: atlas do esporte, educação fisica e atividades físicas de saúde e lazer no Brasil. Rio de Janeiro: Shape, 2005. p. 760-761.

PARKHOUSE, B. L. The management of sport. Its foundation and application. St. Louis: Mobsy Year Book, 1991 apud ZOUANI, D. M.; PIMENTA, R. C. Perfil dos profissionais de administração esportiva no Brasil. In: WORLD SPORT CONGRESS. Barcelona, 2003 Disponível em: <http://www.ebape. fgv.br/academico/asp/dsp_rap_sobre.asp>. Acesso em : 06 jun. 2005.

. The management of sport. Its foundation and application. St. Louis: Mobsy Year Book, second edition, 1996 apud ZOUANI, D. M.; PIMENTA, R. C. Perfil dos profissionais de administração esportiva no Brasil. In:WORLD SPORT CONGRESS, Barcelona, 2003 Espanha. Disponível em: $<$ http://www.ebape.fgv.br/academico/asp/dsp_rap_sobre.asp> Acesso em : 06 de junho de 2005.

ROBBINS, S. Comportamento organizacional. Rio de Janeiro: Livros Técnicos e Científicos, 1999.

WRIGHT, P; KROLL, M. J.; PARNELL, J. Administração estratégica: conceitos. São Paulo: Atlas, 2000.

ZOUANI, D. M.; PIMENTA, R. C. Perfil dos profissionais de administração esportiva no Brasil. In: WORLD SPORT CONGRESS, Barcelona, 2003., Espanha. Disponível em: http://www.ebape.fgv.br/academico/asp/dsp_rap_sobre.asp>. Acesso em: 06 jun. 2005.

ZARIFIAN, P. Objetif compétence. Paris: Liaisons, 1999 apud ZOUANI, D. M.; PIMENTA, R. C. Perfil dos profissionais de administração esportiva no Brasil. In: WORLD SPORT CONGRESS, Barcelona, 2003 Espanha. Disponível em: <http://www.ebape.fgv.br/academico/asp/dsp_rap_sobre.asp>. Acesso em: 06 jun. 2005. 


\section{Tiago Perez Vieira}

Faculdade de Educação Física -UNICAMP

\section{Sérgio Stucchi}

Faculdade de Educação Física - UNICAMP

\section{Referência do artigo:}

\section{ABNT}

VIEIRA T. P., STUCCHI S. Relações preliminares entre a gestão esportiva e o profissional de educação física. Conexões, v.5, n. 2, p. 113-128, 2007.

\section{APA}

Vieira, T. P., \& Stucchi, S. (2007). Relações preliminares entre a gestão esportiva e o profissional de educação física. Conexões, 5(2), 113-128.

\section{VANCOUVER}

Vieira TP, Stucchi S. Relações preliminares entre a gestão esportiva e o profissional de educação física. Conexões, 2007, 5(2): 113-128. 